\title{
Assessing Farm Record Keeping Behaviour among Small-Scale Poultry Farmers in the Ga East Municipality
}

\author{
Enoch Kwame Tham-Agyekum (Corresponding Author) \\ Department of Agricultural Extension \\ University of Ghana-Legon, Accra, Ghana \\ Tel: 233-243-072-673 E-mail: donsprakels@yahoo.com \\ Patrick Appiah \\ Department of Agricultural Economics, Agribusiness and Extension \\ Kwame Nkrumah University of Science and Technology \\ University Post Office, Kumasi, Ghana \\ Tel: 233-242-214-746_E-mail: pappiah35@yahoo.com \\ Fred Nimoh \\ Department of Agricultural Economics, Agribusiness and Extension \\ Kwame Nkrumah University of Science and Technology \\ University Post Office, Kumasi, Ghana \\ Tel: 233-244-111-754 E-mail: frediemoh@yahoo.com
}

\begin{abstract}
The study sought to investigate the farm record keeping behaviour among small-scale poultry farmers in the Ga East Municipality. Data was collected by the use of the simple random sampling technique. All the poultry farmers interviewed kept at least production and financial records. The chi-square test of independence showed that farm record keeping was independent of age, educational level, experience in poultry farming, farmer status, number of birds owned by respondents and respondents' membership of a farmer association. The reason why most of the farmers did not keep all the farm records was because they assert that those records were not beneficial to them. An award for the best farm record keeper must be instituted by the Ministry of Food and Agriculture (MoFA) in collaboration with other non-governmental agencies to help boost farmers' interest in keeping farm records.
\end{abstract}

Keywords: Farm Records, Behaviour, Small-Scale, Poultry, Farmers, Ga East, Municipality

\section{Introduction}

Poultry production is a very important source of livelihoods for most rural communities. This is because it provides ready cash for emergency needs (FASDEP, 2002), supplies the fast-growing human population with high quality protein, contributes significantly to food security, poverty alleviation and ecologically sound management of natural resources (Guẽye, 2002). Since there is a continuing rise in the cost of production of cattle, sheep and goat meat (Onuekwusi, 2001), consumer preferences have shifted now for poultry meat (white meat) given the ecological, economic, social and health advantages it has over the other types of meat (red meat) (Guẽye, 2002).

In the face of the recent global economic crunch and the rapid pace of the farming industry, it is impossible for producers to manage a farm enterprise the way their parents did 30 years ago (Arzeno, 2004). Henderson \& Gomes (1974) noted that one possible approach to improving small-scale farming is through the use of farm records. Without farm records, a farmer will not make it very far in today's business environment. This is because a farmer who maintains an adequate set of records can usually handle problems better than the one who does not (Hansen et al., 1991; Poggio, 2006).

Despite the importance of farm records to the growth of a farm business, farmers often consider it as a difficult task (Poggio, 2006) and therefore the decisions they make are guided by vague estimates and guesses based on 
their past experience of farming (Johl \& Kapur, 2001). This state of affairs warrants a situation where policy formulation, planning agricultural programmes, monitoring and evaluation becomes difficult because data collection from the records of farmers is practically impossible. It is imperative for policy-makers to convey information to producers by demonstration projects, technical assistance, and education programmes. Under a changed political environment, some combination of education and economic incentives could be lower cost and more effective tools for achieving desired environmental conservative goals" (Han-Hong-yun \& Zhao Lian-ge 2009).

This study seeks therefore to assess the farm record keeping behaviour among small-scale poultry farmers in the Ga East Municipality.

\section{Theoretical Framework}

Farm record keeping involves collecting an account of a farmer's daily operations in the farm. There is no universally accepted definition of farm records. However, Torres (2001) gave two definitions for farm record keeping. Record keeping is keeping of detailed records by a farmer of his farm's daily operations, income and expenses. He added that record keeping refers to data collection activity of a research organisation which involves the keeping of records of a group of farmers with some guidance and support from the researcher.

\subsection{Frequency and Use of Farm Records}

According to Devonish et al., (2000) and Aning (2006), most farmers keep their farm records manually. Both stated that the majority of farmers (81\%) kept their records hand written, that is in books, ledgers bills and other loose leaves. Devonish et al., (2000) further stated that $4 \%$ of them store their records on the computer using some type of accounting software and $15 \%$ of the farmers keep both hand written and computerised records.

In a study by Okantah et al., (2003), poultry farmers were asked to determine the frequency with which they collected, inspected, analysed and referred to their farm records. It was noted that most farmers collected farm records on a daily basis but tended to refer to them on a weekly or monthly basis. Thus records were not likely to have an immediate influence on the daily business decision making process by the poultry farmers. Devonish et al., (2000) showed contrary results that most of the farmers (38\%) interviewed for their research work preferred to record their data weekly whiles $30 \%$ preferred monthly basis and $28 \%$ recorded data daily.

\subsection{Types of Farm Records}

There are various types of farm records but Omoruyi, (1999) and Poggio (2006) classified them under four basic types. They are the resource inventories, production records, financial records and supplementary records. Resource inventories include assets and liabilities of the farm whiles production records include mortality, breeding, bird performance, feed information, laying and labour. Financial records include income from sale of eggs and birds and expenditure from feed, vaccines, labour and maintenance of farm equipments. Supplementary records include survey map, the farm layout (map) and the legal documents of the farm. According to Devonish et al., (2000), 84\% of the farmers interviewed kept records on production (feed, egg production, labour, mortality, birth and breeding). Okantah et al., (2003) also found that majority of farmers (96\%) kept production records (weight of birds sold, the amounts of feeds and drugs or vaccines administered). These high percentages prove that most farmers are more concerned about the productivity of their farm business. According to Devonish et al., (2000) and Okantah et al., (2003), it was found that majority of farmers (76\% and 95\%) kept financial records respectively. These show the importance farmers attach to their financial needs.

\subsection{Implications of Keeping Farm Records}

Muhammad et al., (2004) noted that farm record keeping is a key practice used by very successful farmers and vice versa. Essentially, accurate written farm records are very helpful. Chapman (2003) and Iton (1999) stated that a farmer who has a well-kept farm record is in a more favourable position to borrow needed funds than one who has no farm records. This is confirmed by Devonish et al., (2000) that more than half (57\%) of a total of 160 farmers interviewed were obtaining credit due to the fact that they were keeping farm records. It can be said here that their farm records helped them in obtaining the farm loans. However, the $43 \%$ who were not obtaining farm credit were those who did not keep farm records. According to Johl \& Kapur (2001), when farmers keep records, they continuously give the needed information for state and national farm policies such as land and price policies. This further helps in research works which will require precise and correct data which is possible only if proper records are maintained on the farms and included in the study. Farm records therefore serve as a helpful tool in obtaining the correct data for examining and developing sound policies. Farmers must maintain proper farm records in order to receive subsidies from government. This was stated by Rolls (2001) that records of 
building and machinery linked to farm registration in Hungary are essential for access to government subsidies. Again in Lithuania, farmers are also obliged to keep farm records to obtain state support.

\subsection{Factors Affecting Keeping of Farm Records}

Keeping of farm records is affected by certain factors. According to Mariene (1995) and Devonish et al., (2000), farm record keeping is independent of age, gender, farm size, level of formal education and years of farming experience. The research by Devonish et al., (2000) however, further showed that there was a significant relationship between farm record keeping and the following factors: farmer status, the receipt of credit and net income. Farmers who owned the larger farms tended to keep records than those with relatively smaller farms. Full-time farmers also tended to keep farm records than part-time farmers. A higher proportion of farmers who kept records had obtained credit because their farm records were used to provide an indication of the viability of the farm business in order to receive credit from financial institutions. Farmers who keep farm records are likely to have higher incomes.

\subsection{Constraints of Keeping Farm Records}

Farm record keeping is often seen as a mundane task by farmers (Poggio, 2006). Obviously, farmers are faced with constraints which cause their inability to keep farm records. Minae et al., (2003) noted that the lack of keeping farm records is more pronounced due to the high levels of illiteracy and low numeracy levels in most low resource African farming communities. Another constraint faced by farmers is that, most of them engage in several enterprises and mixed farming systems, and thus farm record keeping requires much of their time. They are therefore faced with time constraints which hinder them from keeping farm records (Johl \& Kapur 2001). Johl \& Kapur (2001) further stated that the subsistence nature of farming does not produce any incentive for keeping the farm records. Farmers therefore cannot engage separately trained accountants for helping them in farm accounting. Singh (2001) commented that the small farmers know that because of the small size of their farm holdings they will not be able to effect economies of scale hence do not show interest in farm record keeping. Minae (2001) noted that lack of sensitisation on the importance of farm record keeping on the performance of farm businesses by extension agents or enumerators is a constraint. Johl \& Kapur (2001) further stated that sufficient numbers of trained specialists in farm management are not available who could help farmers maintain records of their business. Johl \& Kapur (2001) stated that farmers are always afraid of new taxes and so they fear that if they maintain records and their incomes show up high in their record books, some sort of high tax may be levied on them.

\section{Objectives}

\subsection{Main Objective}

The main objective of the study is to assess farm record keeping behaviour among small-scale poultry farmers in the Ga East Municipality.

\subsection{Specific Objectives}

The following specific objectives were formulated to help achieve the main objective:

- To examine the demographic characteristics of the poultry farmers

- To examine the various types of farm records kept by the poultry farmers

- To examine the benefits derived from record keeping

- To determine the factors affecting farm record keeping by the poultry farmers

- To identify the constraints of farmers in the area of farm record keeping

\section{Methods}

\subsection{Planning and Development of the Survey}

The study area for this research was the Ga East Municipality in the Greater Accra Region of Ghana. This area was selected due to the presence of numerous small-scale poultry farms in the Municipal (100). The population for the study was made up of all small-scale poultry farmers in the Municipality. The Municipal Directorate of the Ministry of Food and Agriculture was consulted to obtain background information about the poultry farmers in the Municipal.

\subsection{Pre-tests and pilot survey}

A list of the small-scale poultry farmers in the Municipal was obtained from the Oyarifa Livestock Farmers Association (OLFA) and the Oyarifa Area Women Poultry Farmers Association (OAWPFA). These were the 
only farmers' association in the Municipality. Questionnaires were developed and pre-tested with 10 of the 100 small-scale poultry farmers in the Municipal.

\subsection{Final survey's design and plan}

After the pre-test survey, the questionnaires were revised and appropriate corrections were effected to avoid biases and maintain confidentiality of respondents. In order to determine the right sample frame and the correct sample size at $95 \%$ confidence level with $+/-5 \%$ confidence interval, there was the need to hold consultative meetings with executive members of the two farmers' associations in the Municipal. The meeting was also to help gather the necessary documents to help identify the locations of the farmers. Sample sizes were adjusted to achieve a representation of the population since some of the farmers were not available as at the time of data collection.

\subsection{Implementation of survey and data collection}

Due to constraint in time and resources, 50 small-scale poultry farmers were selected using the simple random sampling technique. A research team member was blindfolded and randomly selected the 50 small-scale poultry farm. Primary data was collected through the use of informal interviews with validated structured questionnaires which contained both open and closed ended questions. Secondary data was collected from the Ga East Municipal Directorate of the Ministry of Food and Agriculture, the Oyarifa Livestock Farmers Association (OLFA) and the Oyarifa Area Women Poultry Farmers Association (OAWPFA). Farmers were visited individually in their farms for the collection of data by the team of researchers.

\subsection{Data coding and data-file construction}

In order to ensure reliability and validity of the questionnaires obtained after the data collection, they were edited into an appropriate form and subjected to analysis. The data collected from the respondents was entered into the Statistical Package for the Social Scientist - SPSS (Version 16.0) and the Microsoft Office Excel computer software programmes. Descriptive statistics such as frequency distributions, percentages, mode, means and standard deviations and inferential statistics that is chi-square test of independence were employed to analyse the data.

\section{Results and Discussion}

\subsection{Demographic Characteristics of Respondents}

Data was collected on the demographic characteristics of the respondents. These were age, experience in years, number of birds owned by poultry farmers, sex, educational level of respondents, farmer status and membership of a farmers' association.

\subsubsection{Age}

The mean age of the poultry farmers was 44.5 years. The results showed that most of the poultry farmers are in their active years as over $60 \%$ are below the age of 50 . Contrary to this report is the finding by MAR/IICA Draft Report (1999) which stated that "the rapid ageing of the farm work force is a reflection of disdain among youths for agricultural work".

\subsubsection{Sex}

The male farmers were represented by $72.0 \%$. Females were represented by $28 \%$. Although the ratio of females to males is low, it still shows that women have a fair representation in the poultry industry in the Municipality. Assassie (2008) observed that women may go into farming to meet demands at the home. He further explained that gender has proven to be an essential variable for analysing roles, responsibilities, constraints, opportunities, incentives, costs and benefits in agriculture.

\subsubsection{Farming Experience in years}

The mean years of experience by farmers in poultry farming was 10.52 years. Data shows that poultry farmers have a relatively low experience in poultry farming. This could be because, recently there has being an increased concern shown by the government on the nation's agriculture especially on poultry farming, thereby, making it a viable economic venture. This has attracted new entrants into the poultry business, hence the low experience. Experience is the basis of progress and success in business (Johl \& Kapur, 2001). In the presence of a lack of experience, it is likely to result in low production and income for farmers (Adekoya, 2005). With the relatively low years of experience in farming, farmers are likely not to keep farm records. However, it will be easier for experienced farmers to keep records of their farm activities. 


\subsubsection{Number of Birds}

The mean number of birds owned by respondents was 1691.4 birds. This implies that the majority of the poultry farmers are keeping small number of birds. This situation gives an indication of the level of investment the respondents could put into the poultry business. The small numbers of birds kept by poultry farmers is likely to reflect on their farm record keeping behaviour because according to Johl \& Kapur (2001), the subsistence nature of farming does not produce any incentive for keeping farm records and farmers cannot engage separately trained accountants to help them in farm accounting. Singh (2001) added that small-scale farmers are likely not to show interest in keeping farm records because they know that because of the small size of their farm holdings they will not be able to effect economies of scale.

\subsubsection{Educational Level}

The data suggests that small-scale poultry farmers in the Municipality have a high literacy rate since over $65 \%$ of the farmers had reached the secondary level and beyond. This is likely to reflect on their farm record keeping behaviour since they might have acquired knowledge and skills in poultry farming from their respective educational institutions.

\subsubsection{Farmer Status}

Sixty percent (60\%) of the poultry farmers that were interviewed were into full-time farming whiles $40 \%$ of the respondents were into part-time farming. This may be due to the fact that the poultry business is a lucrative one and the risks involved very high, therefore it needs maximum concentration in terms of its management and production (Adekoya, 2005).

\subsubsection{Membership of an Association}

Majority of the poultry farmers $(60 \%)$ interviewed were members of various farmer associations in the Municipality whiles $40 \%$ did not belong to any farmer association. Members of such associations receive support in the form of cash and subsidies. Educational programmes (seminars, symposium and workshops) also formed a major part of the benefits they receive from such associations. Okantah et al., (2003) noted that poultry farmers with low patronage for farmer associations are often limited in their access to information, goods and services.

\subsection{Distribution of Types of Records}

All respondents (100\%) kept production and financial records whiles $94 \%$ of poultry farmers kept records on the health of their poultry birds, $62 \%$ of poultry farmers kept labour records, $52 \%$ of respondents kept inventory records, $32 \%$ of respondents kept farm records on management practices and $16 \%$ kept supplementary records. Supplementary records include farm maps and farm legal documents. Researches by Okantah et al., (2003) and Devonish et al, (2000) showed that most poultry farmers keep production and financial records. The reason all the poultry farmers kept production and financial records was that they were to provide such farm records when applying for loans from financial institutions (Iton, 1999). Okantah et al., (2003) also showed that these high percentages for production and financial records prove that most farmers are more concerned about the productivity of their farm business.

\subsection{Level of Farm Record Keeping}

Small-scale poultry farmers were graded according to the number of farm records they were keeping. Farmers who were keeping less than three $(<3)$ types of farm records were classified as low record keepers. Farmers who were keeping between three (3) and four (4) were classified as moderate record keepers whiles farmers who were keeping between five (5) and six (6) were classified as high record keepers. Majority of the poultry farmers (52\%) kept a moderate number (3-4) of farm records. Respondents who kept a high number of farm records (5-6) were $44 \%$ whiles $4 \%$ represented poultry farmers who kept the lowest number of farm records. The level of record keeping differs among the poultry farmers. It can be said here that farm record keeping among small-scale poultry farmers in the Municipal is rather encouraging as over $90 \%$ of respondents were beyond the low level of record keeping. However, researches conducted in Zambia, Tanzania, Uganda, Namibia, Swaziland, Malawi, Ghana and Kenya by Minae et al., (2003) and Mahiyu (2008) noted that small-scale farmers rarely keep a record of their farm business.

\subsection{Frequency of Record Keeping}

Sixty-two percent $(62 \%)$ of the poultry farmers preferred to keep their farm records daily whiles $30 \%$ preferred keeping farm records on a weekly basis and $8 \%$ keep farm records monthly. The main reason behind the highest percentage for the daily basis was perhaps due to the fact that farmers needed to keep track of activities on the 
farm, hence, the daily routine (Okantah et al., 2003). However, Devonish et al., (2000) showed that in Barbados, most of the farmers $(38 \%)$ preferred to record their data weekly.

\subsection{Storage of Farm Records}

Majority of respondents (82\%) kept their farm records manually, that is in books, sheets of papers and temporarily on walls to be transferred later into record books whiles $2 \%$ adopted the computerised system only using mainly Microsoft Office Word and Microsoft Office Excel and 16\% tended to use both systems (manual and computerised). Iton (1999) stated that regardless of the form of farm records, from sophisticated computerized systems to rudimentary loose-leaf files, a farm record should provide timely and consistent information to assist the farm management process. The result confirms Aning (2006) and Devonish et al., (2000), that majority of farmers (81\%) claim to keep hand-written records (manually).

\subsection{Implications of Record Keeping}

\subsubsection{Receipt of Farm Credits}

From the data supplied by Table 8 , majority of the respondents (70\%) were obtaining farm credit from financial institutions. According to $30 \%$ of farmers who do not receive farm credit, they could finance their own work without farm loan. Since all poultry farmers interviewed kept at least two types of farm records: namely production and financial records, they all stood a good chance to receive farm credit. Receipt of farm credit is dependent on the ability of the poultry farmer to provide properly kept farm records. This is confirmed by Iton (1999) and Chapman (2003) that farmers have to provide written records of their farm operations to provide an indication of the viability of their business, else obtaining a farm loan may be an uphill battle.

\subsubsection{Farmers Day Awards}

Field data collected showed that the majority of farmers (78\%) were yet to receive the annual farmers' day award whiles $22 \%$ of the poultry farmers interviewed had ever been beneficiaries of the annual farmers' day awards. Keeping of farm records is only one of the criteria for assessment. Without farm records, it will be difficult for a poultry farmer to benefit from the annual farmers' day awards.

\subsection{Factors Affecting the Keeping of Farm Records}

The following variables were tested using the chi-square test of independence: Age, educational level, experience in farming, farmer status, number of birds owned, membership of a farmers' association. All variables were tested at a $5 \%$ level of significance except educational level which was tested at $1 \%$. The following variables were found to be independent of farm record keeping: age, educational level, experience in poultry farming, farmer status, number of birds owned by respondents and respondents' membership of a farmer association. This finding agrees with Mariene (1995) and Devonish et al., (2000) that age, educational attainment and years of farming experience, gender and farm size are independent of record keeping. However, Devonish et al., (2000) showed that record keeping is dependent on the following variables: farmer status, income levels and receipt of farm credit. Full-time farmers also tended to keep farm records than part-time farmers. Farmers who keep farm records are likely to have higher incomes. A higher proportion of farmers who kept records had obtained credit.

\subsection{Constraints of Farmers in Keeping Farm Records}

Farm record keeping is often seen as a mundane task by farmers (Poggio, 2006). Although Muhammad et al., (2004) proved that farm record keeping is a key practice used by very successful farmers; small-scale poultry farmers in the Municipal were not keeping all the types of farm records. Essentially, farmers are faced with constraints which form the basis for their inability to keep farm records. The reason given by most of the poultry farmers $(46 \%)$ on why they do not keep comprehensive farm records was that the records were not beneficial whiles $22 \%$ of respondents also could not give a reason why they did not keep comprehensive farm records. Respondents representing $14 \%$ complained of time constraints. Others (8\%) represent other reasons given by poultry farmers on why they did not keep comprehensive farm records. This included difficulty in entering data into record books due to stress, forgetfulness due to deferred entries, hired personnel who keep farm records cheat on their managers and some workers find it difficult to enter data because of their low educational attainment. Mariene (1995) noted that the main dimensions used by smallholders in deciding whether or not to adopt formal record keeping are its perceived importance and the ease of its practical application in diversified farms. This could account for the reason why most of the respondents (46\%) did not keep comprehensive farm records claiming that those records were not beneficial to them. Devonish et al., (2000) found that $57 \%$ out of 160 farmers did not keep farm records. The main reasons for not keeping records were lack of time (32\%), 
because farming is a hobby (26\%), records not beneficial (16\%), no particular reason (15\%), too old (8\%), afraid to know losses (3\%). See Table 17 for details.

\section{Conclusion}

Based on the findings of the study, the following conclusions are drawn;

- The results show a relatively low participation of women in poultry farming.

- The results show active participation of the youth in poultry farming.

- The data suggests that small-scale poultry farmers in the Municipality have a high literacy rate since over $65 \%$ of the farmers had reached the secondary level and beyond.

- The small number of birds kept by respondents gives an indication of the level of investment the respondents could put into the poultry industry.

- Record keeping in the Municipality is encouraging since all the respondents kept more than two types of farm records.

- All the farmers keep production and financial farm records.

- Most of the farmers keep records on the health of their poultry birds.

- Supplementary records are the least kept record by farmers.

- Most of the poultry farmers are yet to computerise their farm activities.

- Most poultry farmers keep their farm records daily.

- With farm records, farmers can enjoy benefits like access to farm credits and win the annual farmers' day awards.

- The reason why farmers do not keep all the types of farm records are that they claim those records are not beneficial.

\section{Recommendations}

- Women must be encouraged to enter into the poultry business. This can be done by giving an award to the best female. They can also be offered scholarships to study agriculture in higher level institutions. This will help boost their interest in agriculture and their massive participation will be a boost to the nation's agriculture.

- Since most of the respondents are keeping smaller number of birds, financial support must be given to enable them expand their scale of production.

- The Directorate of Agricultural Extension Service (DAES) of the Ministry of Food and Agriculture (MoFA) should still intensify their work on farmers to enable them keep comprehensive farm records. This can be done by organising frequent training programmes and follow-ups to enable poultry farmers keep systematic records.

- Simple data notebooks and data sheets for farm record keeping must be designed for the use of poultry farmers. To ensure practicability, the data notebooks and data sheets need to be developed in consultation with farmers.

- Aside the annual farmers' day awards, an award for the best farm record keeper must be instituted by MoFA in collaboration with other non-governmental agencies to help boost farmers' interest in keeping farm records.

\section{References}

Adekoya, A. E. (2005). Training needs of small scale poultry farmers on improved production techniques, African Journal of Livestock Extension, Vol. 4.

Aning, K. G. (2006). The structure and importance of the commercial and village based poultry in Ghana: Final review report, Food and Agricultural Organization, [Online] Available: www.fao.org, retrieved on $6^{\text {th }}$ April, 2009, 10:30 GMT.

Arzeno, A. (2004). Record Keeping in Farm Management, College of Agriculture and Biological Sciences, South Dakota State University, Brookings.

Assassie, L.K. (2008). Effectiveness of teaching and learning in the agricultural colleges as perceived by stakeholders in the Ashanti Region of Ghana, Kwame Nkrumah University of Science and Technology, KNUST, Kumasi (Unpublished undergraduate thesis). 
Chapman, M. E. N. (2003). Keeping farm records in Sudan, Historical Document, Kansas Agricultural Experiment Station, [Online] Available: www.oznet.ksu.edu, retrieved on $4^{\text {th }}$ November, 2008, 9:00 GMT.

Devonish, E., Pemberton, C. A., Ragbir, S. (2000). Record keeping among small farmers in Barbados, Department of Agricultural Economics and Extension, University of the West Indies, St Augustine, Trinidad and Tobago.

FASDEP 1. (2002). Food and Agriculture Sector Development Policy 1, Ministry of Food and Agriculture.

Guẽye, E.F. (2002). Employment and income generation through family poultry in low-income food-deficit countries, World's Poultry Science Journal, Volume 58, page 541-557, Cambridge University Press, Cambridge Journals Online.

Hansen, J. C., Johnson, D.M., Lesley, B. V. (1991). Developing and improving your farm records, Department of Agriculture, University of Maryland.

Han-Hong-yun \& Zhao Lian-ge. (2009). Farmer characters' and behaviour of fertilizer application-Evidence from a survey of Xinxiang County, Henan Province, China. Agricultural Sciences in China 8:10, 1238-1245.

Henderson, T. H., \& Gomes, P.I. (1979). Profiles of Small Farming in St. Vincent, Dominica and St. Lucia: Report of a Baseline Survey, Barbados.

Iton, A. (1999). Small Farmer Participation in Export Targeting Production in the Windward Islands, OECS/EDU, Roseau, Dominica.

Johl, S. S., \& Kapur, T.R. (2001). Fundamentals of Farm Business Management, Kalyani Publishers, pp 253-259.

Mahiyu, A. (2008). Financial management for smallholder farmers, Farm Radio International script of the week, Issue \#16, Reviewed by: Rex Chapota.

Mariene, C. (1995). An exploratory study on smallholders' perceptions of farm records in the Embu district of Kenya: A repertory grid technique, Curtin University of Technology, [Online] Available: www.muresk.curtin.edu, retrieved on $6^{\text {th }}$ April, 2009, 11:30 GMT.

Minae, S., Baker, D., Dixon, J. (2003). Status of Farm Data Systems and Farmer Decision Support in Sub-Saharan Africa, FAO Rome, 2008.

Muhammad, S., Tegegne, F., Ekanem, E. (2004). Factors Contributing to Success of Small Farm Operations in Tennessee, Institute of Agricultural and Environmental Research Tennessee State University Nashville, Tennessee, Journal of Extension, Volume 42 (4).

MAR/IIRA. (1999). A Draft Sondeo Executive Summary conducted in Barbados, Ministry of Agriculture and Rural Development, Barbados.

Okantah, S.A., Aboe, P.A.T., Boa-Amponsem, K., Dorward, P.T., Bryant, M. J. (2003). Small-scale chicken keeping in peri-urban Accra and Kumasi, Final Technical Report of United Kingdom Department for International Development (DFID)-funded Project 74pp, DFID. R7631, Livestock Production Research Programme.

Omoruyi, S. A., Orhue, U. X., Akerobo, A. A., Aghimien, C. I. (1999). Prescribed Agricultural Science for Senior Secondary Schools, Revised Edition, Idodo Umeh Publishers Limited, Benin City.

Onuekwusi, G. C. (2001). Adoption of Improved Rabbit Technologies by Farmers in Akwa-Ibom State Nigeria Implications for Extension. Proceedings of 36th Annual Conference, Agric. Society of Nigeria F.U.T. Owerri Oct. 20-24, pp: 368-371

Poggio, M. (2006). Farm Management Records, [Online] Available: www.srdc.gov.au, retrieved on 4th November, 2008, 9:20 GMT.

Rolls, M. J. (2001). Review of Farm Management in Extension Programmes in Central and Eastern Europe Countries, Food and Agriculture Organization of the United Nations Rome, Italy.

Schlender, J. R. (1991). Farm Record Keeping, Kansas State University Agricultural Experiment Station and Cooperative Extension Service.

Singh, I.J. (2001). Farm Management in Agricultural Extension in India, CSS Haryana Agricultural University, Hisar-125004, India (unpublished).

Torres, A.B.D. (2001). Farm Management in Extension in the Philippines, FAO, Rome (unpublished). 
Table 1. Demographic Characteristics 1

\begin{tabular}{|l|c|c|c|c|c|}
\hline Demographic & Maximum & Minimum & Mode & Mean & Standard Deviation \\
\hline Age (years) & 72 & 23 & 43 & 44.54 & 10.114 \\
\hline Experience (years) & 32 & 1 & 10 & 10.52 & 7.465 \\
\hline Number of Birds & 5000 & 120 & 500 & 1721.4 & 1422.315 \\
\hline
\end{tabular}

SOURCE: Field Data, 2009

The table describes the demographic characteristics of respondents. They include age, experience in farming and number of birds kept by farmers.

Table 2. Demographic Characteristics 2

\begin{tabular}{|l|c|c|c|}
\hline Demographic & Representation & Frequency & Percentage \\
\hline \multirow{3}{*}{ Sex } & Male & 36 & 72.0 \\
\cline { 2 - 4 } & Female & 14 & 28.0 \\
\hline \multirow{5}{*}{ Education } & No Formal Education & 3 & 6.0 \\
\cline { 2 - 4 } & Basic (Primary/JHS) & 13 & 26.0 \\
\cline { 2 - 4 } & SHS/Tech/Voc & 17 & 34.0 \\
\cline { 2 - 4 } & Post Secondary & 10 & 20.0 \\
\cline { 2 - 4 } & Tertiary & 7 & 14.0 \\
\hline \multirow{4}{*}{ Farmer Status } & Full-Time & 30 & 60.0 \\
\hline \multirow{2}{*}{ Membership of Association } & Part-Time & 20 & 40.0 \\
\cline { 2 - 4 } & Yes & 30 & 60.0 \\
\cline { 2 - 4 } & No & 20 & 40.0 \\
\hline
\end{tabular}

SOURCE: Field Data, 2009

The table describes the demographic characteristics of respondents. They include sex, educational level, farmer status and membership of a farmers' association.

Table 3. Types of Farm Records

\begin{tabular}{|l|c|c|}
\hline Type of Farm Records & Frequency & Percent \\
\hline Production Records & 50 & 100.0 \\
\hline Financial Records & 50 & 100.0 \\
\hline Inventory Records & 26 & 52.0 \\
\hline Health Records & 47 & 94.0 \\
\hline Labour Records & 31 & 62.0 \\
\hline Management Practices Records & 16 & 32.0 \\
\hline Supplementary Records & 8 & 16.0 \\
\hline
\end{tabular}

SOURCE: Field Data, 2009

NB: Distribution exceeds 50 because the farmers kept more than two types of farm records.

The table describes the types of farm records that are kept by the poultry farmers. The farm records include; production, financial, inventory, health, labour, management practices and supplementary records. 
Table 4. Level of Record Keeping

\begin{tabular}{|l|c|c|}
\hline Level of Record Keeping & Frequency & Percent \\
\hline Low (1-2) & 2 & 4.0 \\
\hline Moderate (3-4) & 26 & 52.0 \\
\hline High (5-6) & 22 & 44.0 \\
\hline Total & 50 & 100.0 \\
\hline
\end{tabular}

Source: Field Data, 2009

The table above shows the level of record keeping among the poultry farmers. There are three levels; low, moderate and high. The low level represents farmers who keep less than three types of farm records. The moderate level represents farmers who keep three or four types of farm records. The high level represents farmers who keep five or six farm records.

Table 5. Frequency of Record Keeping

\begin{tabular}{|l|c|c|}
\hline Frequency of Record Keeping & Frequency & Percent \\
\hline Daily & 31 & 62.0 \\
\hline Weekly & 15 & 30.0 \\
\hline Monthly & 4 & 8.0 \\
\hline Total & 50 & 100.0 \\
\hline
\end{tabular}

SOURCE: Field Data, 2009

The table above shows the frequency with which farmers keep their farm records.

Table 6. Storage of Farm Records

\begin{tabular}{|l|c|c|}
\hline Storage of Farm Records & Frequency & Percent \\
\hline Manually & 41 & 82.0 \\
\hline Computerised & 1 & 2.0 \\
\hline Both & 8 & 16.0 \\
\hline Total & 50 & 100.0 \\
\hline
\end{tabular}

SOURCE: Field Data, 2009

The table above shows the types of storage systems farmers use in keeping their farmers.

Table 7. Receipt of Farm Credit

\begin{tabular}{|l|c|c|}
\hline Farm Credit & Frequency & Percent \\
\hline Receive & 35 & 70.0 \\
\hline Do not receive & 15 & 30.0 \\
\hline Total & 50 & 100.0 \\
\hline
\end{tabular}

SOURCE: Field Data, 2009

The table above shows the number of farmers who have received farm credit as a result of the farm records they keep. 
Table 8. Farmers Day Awards

\begin{tabular}{|l|l|l|}
\hline Farmers Day Awards & Frequency & Percent \\
\hline Yes & 11 & 22.0 \\
\hline No & 39 & 78.0 \\
\hline Total & 50 & 100.0 \\
\hline
\end{tabular}

SOURCE: Field Data, 2009

The table above shows the number of farmers who have received the annual farmers' day awards as a result of their ability to keep proper farm records. Record keeping is only one of the criteria for assessment.

Table 9. Reasons for Not Keeping Farm Records

\begin{tabular}{|l|c|c|}
\hline Reasons & Frequency & Percent \\
\hline No time & 7 & 14.0 \\
\hline Records not beneficial & 23 & 46.0 \\
\hline Cumbersome nature & 5 & 10.0 \\
\hline No particular reason & 11 & 22.0 \\
\hline Others & 4 & 8.0 \\
\hline Total & 50 & 100.0 \\
\hline
\end{tabular}

SOURCE: Field Data, 2009

The table above shows the reasons who farmers are not able to keep comprehensive farm records. 